\title{
Lanthanide-based metal-organic framework nanosheets with unique fluorescence quenching properties for two-color intracellular adenosine imaging in living cells
}

\author{
Huai-Song Wang ${ }^{1,2}$, Jian $\mathrm{Li}^{1}$, Jin-Yi Li ${ }^{1}$, Kang Wang ${ }^{1}$, Ya Ding ${ }^{2}$ and Xing-Hua Xia ${ }^{1}$ \\ Two-dimensional (2D) materials have attracted tremendous interest as fluorescence quenchers of dye-labeled biomolecules for \\ application in biosensing. Metal-organic framework (MOF) nanosheets, as a new type of 2D material, have rarely been studied as \\ bioanalytical platforms. Herein, we synthesize a series of ultrathin lanthanide-based MOF (MOF-Ln) nanosheets as a dye-labeled \\ aptamer platform. The fluorescence quenching or recovery on the MOF-Ln nanosheets is determined by the charge properties \\ (positive or negative) of the labeled fluorophores. The negatively charged fluorophores experience a fluorescence 'turn-down \\ followed by turn-down' process, whereas the positively charged fluorophores experience a fluorescence 'turn-down followed by \\ turn-up' process. The interesting fluorescence quenching properties of the MOF-Ln nanosheets make them an excellent two-color \\ sensing platform for the intracellular detection of biomolecules.
}

NPG Asia Materials (2017) 9, e354; doi:10.1038/am.2017.7; published online 10 March 2017

\section{INTRODUCTION}

Two-dimensional (2D) nanomaterials have been attracting extensive research interest due to their unique physical and chemical properties, as well as their potential scientific and technological applications in the fields of gas storage, sensing, electronics, energy conversion and storage, and electrocatalysis. ${ }^{1}$ In the area of biomedical applications, 2D nanosheets with an extremely high surface area, such as graphene and its derivative graphene oxide, have been successfully used for biomedical imaging, drug delivery and cancer therapy. ${ }^{2,3}$ Other emerging nanosheets (for example, $\mathrm{MoS}_{2}, \mathrm{WS}_{2}$ and $\mathrm{MnO}_{2}$ ) with a good fluorescence-quenching ability also exhibit selective adsorption affinity toward single-stranded DNA ( $s$ DNA) versus double-stranded DNA ( $d s$ DNA). ${ }^{4-7}$ These results have inspired studies to exploit the potential biological applications of novel 2D nanosheets. Very recently, 2D metal-organic framework (MOF) thin films or nanosheets have been successfully synthesized and exfoliated by several groups. ${ }^{8-10}$ Their potential biological applications remain to be explored.

MOFs are a fascinating class of functional materials that have been extensively studied for applications in gas storage, ${ }^{11}$ catalysis, ${ }^{12}$ separation $^{13}$ and sensing. ${ }^{14}$ MOFs are certainly very promising for fabricating multifunctional luminescent sensors, because both the metal and the ligand units can provide platforms for generating luminescence and some guest molecules loaded on the MOFs can also emit or induce luminescence. ${ }^{14} \mathrm{~A}$ variety of MOFs have been already designed and synthesized for chemical and biochemical sensing. ${ }^{15}$ Their micrometer-sized single crystals or polycrystalline powders limit their applications in biological systems, especially in vivo imaging and drug release. Therefore, a particular interest has been focused on miniaturizing the structures of MOFs to a nanometer-scale regime. ${ }^{16,17}$

Compared with existing nanomaterials (such as inorganic quantum dots, Au nanoparticles and organic liposomes and polymers), nanoscaled MOFs (NMOFs) have potential advantages as novel platforms for nanomedicine. On the one hand, NMOFs exhibit a higher level of structural tailorability (including pore size, shape and morphology) by properly selecting and combining metal ions and bridging ligands. On the other hand, NMOFs are intrinsically biodegradable after completing an intended task. Recently, several NMOFs have been explored as nanocarriers for biomedical imaging and drug delivery. ${ }^{18-24}$ Lin and colleagues $^{19,23}$ employed NMOFs to release drugs or to generate cytotoxic reactive oxygen (for example, ${ }^{1} \mathrm{O}_{2}$ ) species for cancer therapy. ${ }^{22}$ They also used fluorescent NMOFs for real-time intracellular $\mathrm{pH}$ sensing in live cells. ${ }^{20}$ Although their study is still in its infancy, NMOFs have exhibited great potential as a new type of therapeutic and/or bioimaging platform.

Considering the good biodegradable characteristics and structural tailorability of NMOFs, we prepared a series of novel lanthanide-based MOF (MOF-Ln) nanosheets and explored their use as a fluorescence-

\footnotetext{
${ }^{1}$ State Key Laboratory of Analytical Chemistry for Life Science and Collaborative Innovation Center of Chemistry for Life Sciences, School of Chemistry and Chemical Engineering, Nanjing University, Nanjing, China and ${ }^{2}$ Department of Pharmaceutical Analysis, China Pharmaceutical University, Nanjing, China

Correspondence: Professor X-H Xia, State Key Laboratory of Analytical Chemistry for Life Science and Collaborative Innovation Center of Chemistry for Life Sciences, School of Chemistry and Chemical Engineering, Nanjing University, 22 Hankou Road, Nanjing 210093, China.

E-mail: xhxia@nju.edu.cn

Received 18 July 2016; revised 14 November 2016; accepted 20 November 2016
} 
labeled aptamer-based sensing platform to detect DNA and small biomolecules. Bulk MOF-Ln crystals were prepared using 2,2'thiodiacetic acid $\left(\mathrm{S}\left(\mathrm{CH}_{2} \mathrm{COO}\right)_{2}{ }^{2-}\right.$, TDA $)$ as the bridging ligand. Using the lithium intercalation method, ${ }^{25}$ MOF-Ln crystals were exfoliated into ultrathin MOF-Ln nanosheets. As DNA nanocarriers, the MOFLn nanosheets adsorbed a dye-labeled ssDNA probe via the van der Waals force, which decreased the fluorescence intensity of the dyes (tetramethylrhodamine (TAMRA) and fluorescein (FAM)) due to the charge transfer from the dye molecules to the lanthanum ions. If target DNA was present, it hybridized with the dye-labeled DNA on the MOF-Ln nanosheets. The formed dye-labeled $d s$ DNA detached from the MOF-Ln nanosheets due to the decreased adsorption affinity caused by the rigidity of the double-chain structure, resulting in the recovery of the fluorescence of TAMRA- $d s \mathrm{DNA}$, as already observed in traditional 2D nanoprobes. ${ }^{26,27}$ However, the fluorescence of FAMlabeled $d s \mathrm{DNA}$ was further quenched unexpectedly. The phenomena demonstrated that after hybridization with the target DNA, the TAMRA-ssDNA experienced a 'turn-up' fluorescence response, while a 'turn-down' response occurred with FAM-ssDNA.

Inspired by these findings, we designed an adenosine- 5 '-triphosphate (ATP)-aptamer/MOF-Ln nanosheet complex, to monitor ATP activity in living cells. ATP aptamers labeled with FAM and TAMRA were used to assemble multiple dye-aptamer/MOF-Ln nanosheets. By adjusting the molecular ratio of TAMRA-aptamer to FAM-aptamer loaded on the dye-aptamer/MOF-Ln nanosheets, they were used as two-color nanoprobes for assaying ATP activity. The dye-aptamer/ MOF-Ln nanosheets gave a kelly green fluorescence color in the beginning. After interaction with ATP, the aptamer changed into internal loop structures and detached from the MOF-Ln nanosheets, leading to a change in fluorescence color to reddish orange ('turn-up' for the TAMRA-aptamer and 'turn-down' for the FAM-aptamer). In addition, the dye-aptamer/MOF-Ln nanosheets were successfully employed to target intracellular ATP. The results demonstrate that the two-color nanoprobe gives a sensitive change of fluorescence or color for ATP and promises to be an ideal diagnostic method for measuring ATP in living cells.

\section{EXPERIMENTAL PROCEDURES}

\section{Synthesis of MOF-Lns}

A mixture of TDA $(0.8 \mathrm{mmol})$ and $\mathrm{La}\left(\mathrm{NO}_{3}\right)_{3}(0.4 \mathrm{mmol})\left(\mathrm{Nd}\left(\mathrm{NO}_{3}\right)_{3}\right.$, Eu $\left(\mathrm{NO}_{3}\right)_{3}, \mathrm{~Tb}\left(\mathrm{NO}_{3}\right)_{3}$ and $\mathrm{Er}\left(\mathrm{NO}_{3}\right)_{3}$ was also used) was dissolved in $20 \mathrm{ml} \mathrm{NaOH}$ solution $(75 \mathrm{~mm})$ and sealed in a $30 \mathrm{ml}$ vial. The mixture was reacted at $140{ }^{\circ} \mathrm{C}$ for $24 \mathrm{~h}$.

\section{Exfoliation of MOF-Lns}

The exfoliation of MOF-Lns was performed as follows: $5 \mathrm{mg}$ of MOF-Ln precursor was suspended in $2 \mathrm{ml} \mathrm{EtOH}$. The mixture was ultrasonicated for $30 \mathrm{~min}$. The partially exfoliated MOF-Lns were then collected by centrifugation at a speed of 8000 r.p.m. and washed with $n$-hexane twice. For further exfoliation, the collected MOF-Lns were suspended in $10 \mathrm{ml}$ of $0.16 \mathrm{M}$ $n$-butyllithium in hexane and stirred for $20 \mathrm{~h}$ at $25^{\circ} \mathrm{C}$ under $\mathrm{N}_{2}$ atmosphere. The MOF-Lns intercalated with $\mathrm{Li}$ were subsequently placed in EtOH/ $\mathrm{H}_{2} \mathrm{O}$ $(9 / 1, v / v)$ for $1 \mathrm{~h}$. The final prepared MOF-Ln nanosheets were obtained by centrifugation (14 000 r.p.m.).

\section{Fluorescent DNA sensing}

In a typical measurement, a fluorescent probe P1 (20 nM FAM-P1 or $15 \mathrm{nM}$ TAMRA-P1) was mixed with the MOF-Ln nanosheets $\left(0.2 \mathrm{mg} \mathrm{ml}^{-1}\right)$ in $10 \mathrm{~mm}$ phosphate-buffered saline (PBS) buffer (pH 7.4) containing $100 \mathrm{~mm} \mathrm{NaCl}$ and $4 \mathrm{~mm} \mathrm{MgCl}_{2}$ for $5 \mathrm{~min}$. Afterward, target DNA T1 with different concentrations (from 2 to $50 \mathrm{~nm}$ ) was added to the mixture and hybridized with P1 for $5 \mathrm{~min}$ at room temperature. The fluorescence of the mixture was measured.

\section{Fluorescent adenosine detection}

A FAM-labeled AAA (FAM-P2, 20 nM) or TAMRA-labeled AAA (TAMRA-P2, $15 \mathrm{nM})$ fluorescent probe was incubated with MOF-La nanosheets $\left(0.2 \mathrm{mg} \mathrm{ml}^{-}\right.$ ${ }^{1}$ ) in $10 \mathrm{~mm}$ PBS buffer (pH 7.4) containing $100 \mathrm{~mm} \mathrm{NaCl}$ and $4 \mathrm{~mm} \mathrm{MgCl}_{2}$ for 5 min. Afterward, an ATP (uridine triphosphate, guanosine triphosphate, cytidine triphosphate, glutathione, human serum albumin, ascorbic acid or histamine) solution with an appropriate concentration (30 nM for FAM-P2 +MOF-La solution and $25 \mathrm{~nm}$ for TAMRA-P2+MOF-La solution) was added to the P2+MOF-La solution. After allowing the mixture to incubate for $10 \mathrm{~min}$ at room temperature, the fluorescence spectra of the mixture were recorded.

\section{Cell culture}

MCF-7 human breast cancer cells were cultured in Dulbecco's modified Eagle's medium with $10 \%$ fetal bovine serum, $5 \%$ penicillin streptomycin glutamine and $5 \%$ sodium pyruvate (all from GIBCO, Grand Island, NY, USA) at $37^{\circ} \mathrm{C}$ in a humidified atmosphere containing $5 \% \mathrm{CO}_{2}$.

\section{Two-color adenosine imaging in living cells}

The dye-labeled AAA+MOF-La complex (Dye-P2+MOF-La) was prepared as follows: $2 \mu$ FAM-P2 $(25 \mu \mathrm{M})$ and $2 \mu$ T TAMRA-P2 $(25 \mu \mathrm{M})$ were added to $1 \mathrm{ml}$ PBS buffer (0.01 M, pH 7.4) containing $100 \mathrm{mM} \mathrm{NaCl}$ and $4 \mathrm{mM} \mathrm{MgCl}_{2}$. MOFLa nanosheets $\left(0.2 \mathrm{mg} \mathrm{ml}^{-1}\right)$ were then added to the mixture. The mixture was stirred for $2 \mathrm{~h}$ at room temperature. The prepared Dye-P2+MOF-La was collected by centrifugation (14000 r.p.m.) and redispersed in $10 \mathrm{ml}$ PBS $(0.01 \mathrm{M}, \mathrm{pH} 7.4)$ containing $100 \mathrm{~mm} \mathrm{NaCl}$ and $4 \mathrm{~mm} \mathrm{MgCl}_{2}$ with a final concentration of $0.1 \mathrm{mg} \mathrm{ml}^{-1}$ for further intracellular experiments.

One day before imaging, cells were seeded into six-well plates to obtain a suitable density. Then, $20 \mu$ l Dye-P2+MOF-La stock solution were added to the wells and incubated for $4 \mathrm{~h}$ to prepare Dye-P2+MOF-La-uptaken MCF-7 cells. Before imaging, FMD (final concentration: $300 \mathrm{nM}$ ) was added to the wells and incubated for $30 \mathrm{~min}$ for mitochondria imaging. Afterward, the old Dulbecco's modified Eagle's medium was removed and washed with PBS buffer $(0.01 \mathrm{M}$, $\mathrm{pH}$ 7.4) three times. The images were obtained using a confocal fluorescence microscope.

\section{RESULTS AND DISCUSSION}

\section{Crystallization of MOF-Lns}

The Ln coordination polymers were hydrothermally synthesized from $\mathrm{Ln}\left(\mathrm{NO}_{3}\right)_{3}(\mathrm{Ln}=\mathrm{La}, \mathrm{Nd}, \mathrm{Eu}, \mathrm{Tb}$ and $\mathrm{Er})$ and TDA ligand in sodium hydroxide solution. Crystalline products (MOF-La, MOF-Nd, MOF$\mathrm{Eu}$ and MOF-Tb) were obtained (Supplementary Figure S1). The structures of the crystalline MOF-Ln samples were monitored by powder X-ray diffraction. As shown in Figure 1a, the crystalline MOFTb corresponded well with MOF-Eu $\left\{\left[\mathrm{Eu}_{2}(\mathrm{TDA})_{3}\right] \cdot 2 \mathrm{H}_{2} \mathrm{O}\right\}$, which was prepared in our previous work ${ }^{28}$ (Figure $1 \mathrm{~b}$ ), but differed from MOF$\mathrm{La}$ and MOF-Nd. This difference in structures of MOF-Ln samples might result from the lanthanide contraction. ${ }^{29}$ Single-crystal X-ray diffraction data showed that MOF-La crystallized in the orthorhombic space group $\mathrm{Pbcn}$ and was formulated as $\left[\mathrm{La}_{2}(\mathrm{TDA})_{3}\right] \cdot 2 \mathrm{H}_{2} \mathrm{O}$, with a coordination structure not entirely the same as that of MOF-Eu (Supplementary Table S1). The simplified unit cell structure of MOF$\mathrm{La}$ is shown in Figure 1c; $\mathrm{La}^{3+}$ ions were coordinated by nine oxygen atoms and one sulfur atom. The bridging of the TDA chains by the $\mathrm{La}^{3+}$ centers created sheets, forming layered structures as in Figure 1d and Supplementary Figure S2. According to the Fourier transform infrared spectra, the peaks originated from the $\mathrm{COO}^{-}$group of the coordinated TDA ligand were at 1650 and $1566 \mathrm{~cm}^{-1}$ for all the MOF-Lns. The results showed that the $\mathrm{Ln}^{3+}$ ions $\left(\mathrm{La}^{3+}, \mathrm{Nd}^{3+}, \mathrm{Eu}^{3+}\right.$ and $\mathrm{Tb}^{3+}$ ) were coordinated with TDA in the same way (Supplementary Figure S3). As shown in the scanning electron microscopy images, all the MOF-Lns were bulked with 2D layers (Figure 2a1 and Supplementary Figure S4). 


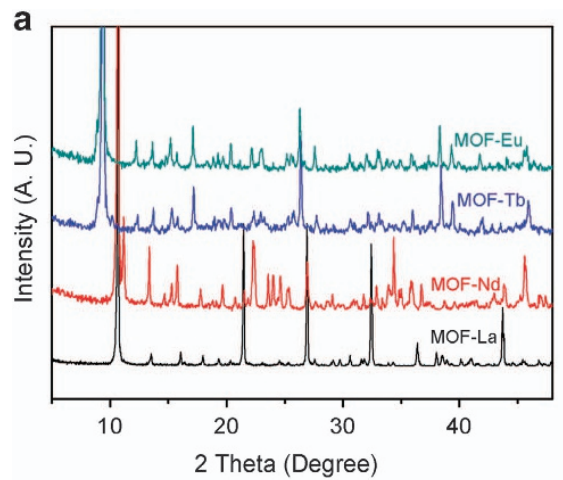

C
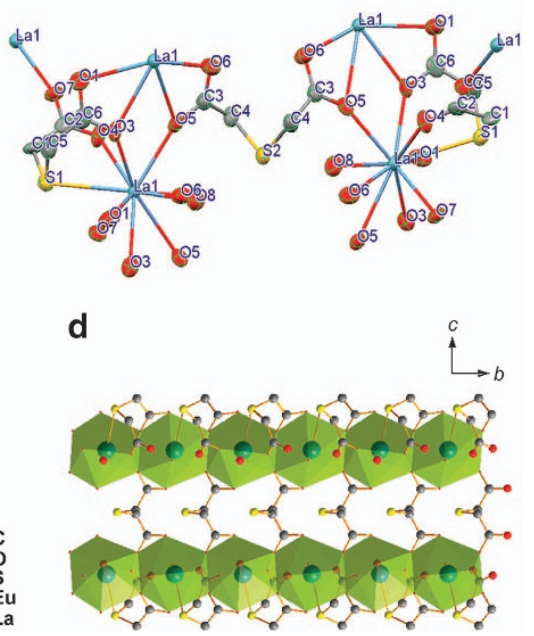

Figure 1 Structural characterization of the MOF-Lns. (a) powder X-ray diffraction patterns of MOF-Lns. (b) The 3D lamellar structure of MOF-Eu viewed along the a-axis. (c) The coordination environment of MOF-La. (d) The 3D lamellar structure of MOF-La viewed along the a axis.
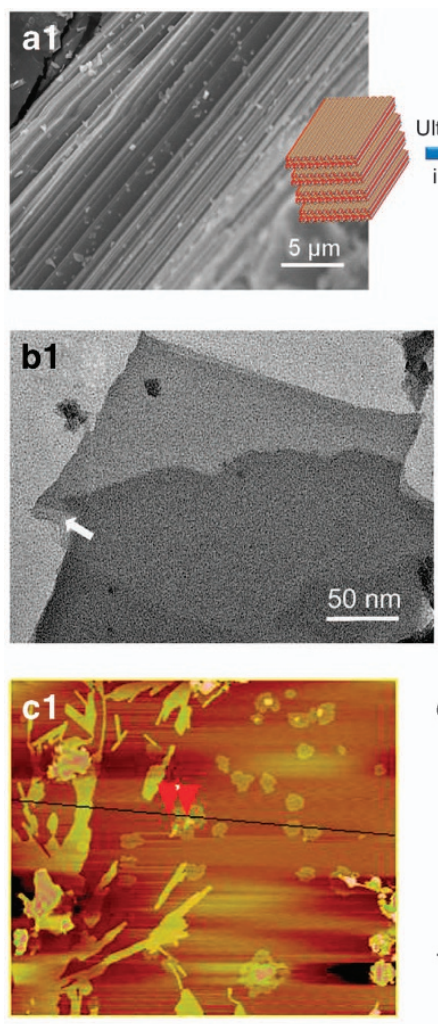
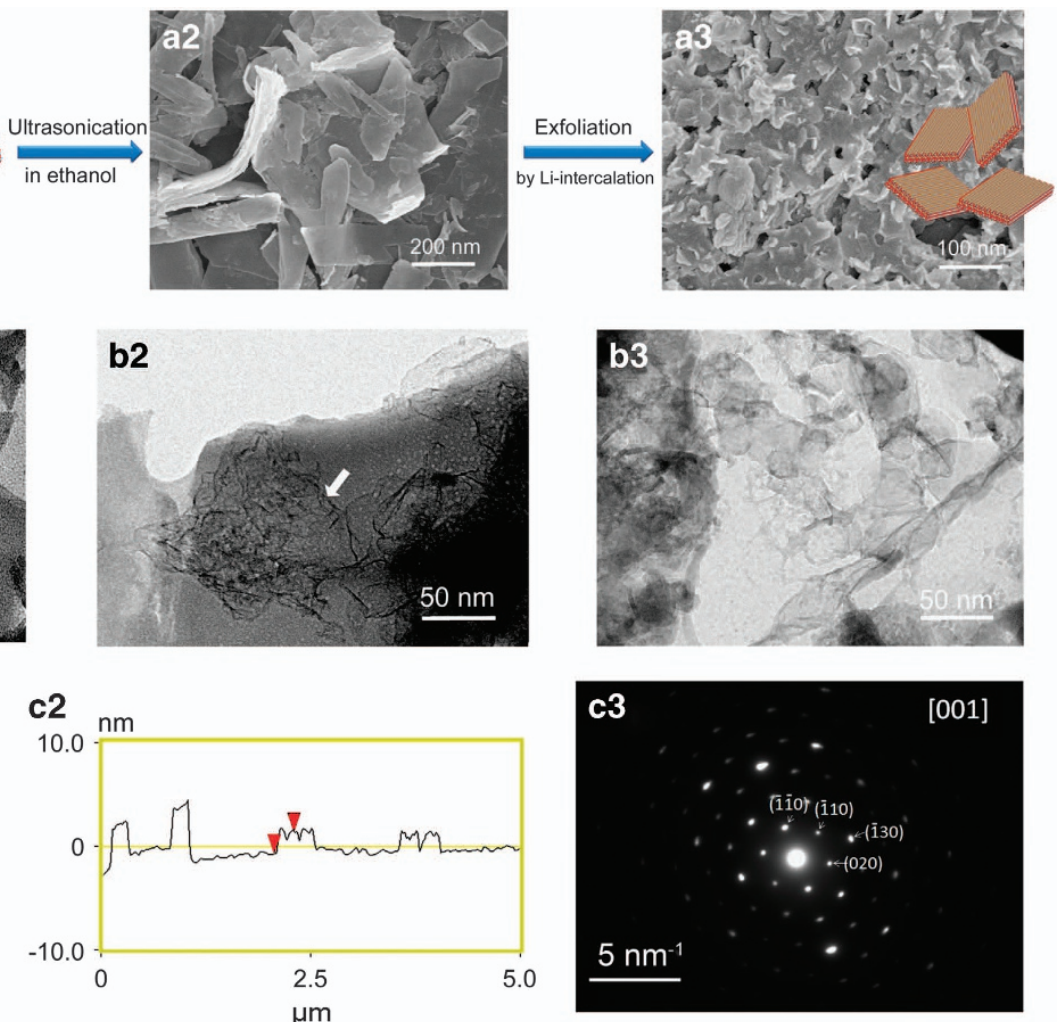
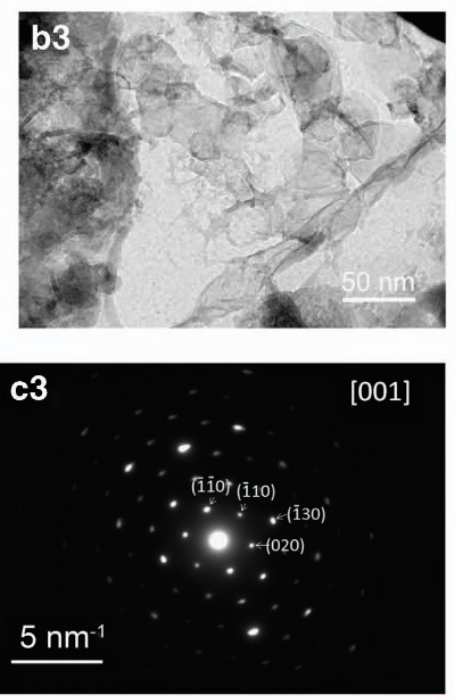

Figure 2 Exfoliation and characterization of MOF-Ln nanosheets. (a1) Scanning electron microscopy (SEM) image of MOF-La in the bulk state. (a2 and b1) SEM and TEM images of MOF-La nanosheets prepared by ultrasonication for 30 min. (a3, b2 and b3) SEM and TEM images of MOF-La nanosheets prepared by the Li-intercalation method. (c1 and c2) Typical atomic force microscopy image and associated height profile of MOF-La nanosheets. (c3) Selected area electron diffraction pattern of the MOF-La nanosheet.

Exfoliation of layered MOF-Ln nanosheets.

The MOF-Ln crystals could not be directly dispersed in solvents (including organic solvents and water) by simply relying on the solvents to minimize the energy of exfoliation. Thus, different exfoliation methods were investigated to prepare highly dispersible
2D MOF nanosheets. Using MOF-La as an example, the layered MOFLa was partially exfoliated into nanoparticles via ultrasonication in ethanol for $10 \mathrm{~min}$ (Supplementary Figure S5). With the increase of ultrasonication time to $30 \mathrm{~min}$, multilayered nanosheets were obtained (Figure $2 \mathrm{a} 2$ and b1). Li-intercalated bulk materials (such as $\mathrm{MoS}_{2}$ and 
$\mathrm{WS}_{2}$ ) can be exfoliated into monolayers via forced hydration..$^{25,30-32}$ The structures of MOF-Lns are very similar to $\mathrm{MoS}_{2}$ or $\mathrm{WS}_{2}$, especially the MOF-Eu and MOF-Tb (Supplementary Figures S6 and S7). In the present study, we used the Li-intercalation method to further exfoliate the multilayered MOF-Ln nanosheets. As shown in Figure 2b2, ultrathin MOF-La nanosheets were obtained when the reaction of bulk MOF-La with $n$-butyllithium was continued for $10 \mathrm{~h}$. When the reaction time was prolonged to $20 \mathrm{~h}$, MOF-La nanosheets were fully exfoliated and more nanosheets were obtained (Figure 2a3 and b3).

Results from selected area electron diffraction pattern and atomic force microscopy indicated that the prepared MOF-La nanosheet was a crystalline sheet structure with an ultrathin thickness of $c a .2 .0 \mathrm{~nm}$ (Supplementary Figure S8 and Figure 2c1-c3), and that the size of most of the exfoliated MOF-La nanosheets was smaller than $500 \times 500 \mathrm{~nm}$. Our results showed that the MOF-La nanosheets exfoliated by the Li-intercalation method were approximately one to three layers and more than 50\% were one-layer nanosheets (Supplementary Figure S9). In addition, our results showed that MOF-Nd, MOF-Eu and MOF-Tb nanosheets could also be exfoliated using the same Li-intercalation method (Supplementary Figure S10).

MOF-Ln nanosheets as fluorescence quenchers of dye-labeled DNA The fluorescence quenching ability of the prepared MOF-Ln nanosheets was evaluated using dye-labeled $s s \mathrm{DNA}$ (P1, as a probe for a Homo sapiens tumor suppressor gene). Figure 3 shows the typical fluorescence emission spectra of TAMRA-P1 and FAM-P1 in $10 \mathrm{~mm}$ PBS, containing different concentrations of target DNA T1, upon addition of MOF-La nanosheets. In the case of TAMRA-P1, the fluorescence intensity decreased rapidly when the MOF-La nanosheets were added into the aptamer solution of $15 \mathrm{~nm}$ (Figure 3a), which was similar to the phenomenon observed for other 2D nanosheets (graphene, graphene oxide or $\mathrm{MoS}_{2}$ ). After hybridization with target DNA T1, a strong fluorescence emission was recovered (Figure 3a). The recovery efficiency increased with the concentration of target DNA T1. This phenomenon demonstrated that the affinity of MOF-La nanosheets for $d s \mathrm{DNA}$ was weaker than for ssDNA. In the case of FAM-P1, however, a different fluorescence-quenching phenomenon was observed. It was expected that the fluorescence intensity of FAMP1 would decrease after mixing with MOF-La nanosheets. After hybridization with T1, the fluorescence of FAM groups was further quenched (Figure $3 \mathrm{~b}$ ), instead of the fluorescence recovery observed for TAMRA-P1. The quenching efficiency increased with the concentration of the FAM-P1 probe.

In addition, the specificity of the dye-labeled $\mathrm{P} 1$ probe was studied using three types of DNA sequences, including the perfectly complementary target T1, a single-base mismatched sequence MT1-1 and a six-base mismatched sequence MT1-2. As shown in Supplementary Figure S11, the dye-labeled P1 probe performed well, discriminating the T1 and the mismatched stands (MT1-1 and MT1-2).

For the MOF-Nd, MOF-Eu and MOF-Tb nanosheets, we found similar fluorescence-quenching properties as in the case of the MOFLa nanosheets (Supplementary Figure S12). However, the fluorescence quenching capability of MOF-Ln nanosheets decreased with the lanthanide contraction. As shown in Figure $4 \mathrm{a}$, the fluorescencequenching efficiency of TAMRA-P1 on MOF-Ln nanosheets decreased from approximately $55 \%$, to $47 \%, 32 \%$ and $23 \%$ with the decrease in ionic radius from $\mathrm{La}^{3+}(1.0 \AA)$, to $\mathrm{Nd}^{3+}(0.98 \AA), \mathrm{Eu}^{3+}(0.95 \AA)$ and $\mathrm{Tb}^{3+}(0.92 \AA)$ ions, respectively. Compared with other $2 \mathrm{D}$ materials (for example, graphene oxide and $\mathrm{MoS}_{2}$ ), 5,33,34 the fluorescencequenching ability of all the MOF-Ln nanosheets was inferior. We suppose that the fluorescence quenching that occurs on MOF-Ln nanosheets is based on a charge transfer from the fluorescent molecules to the lanthanum ions. When FAM-ssDNA or TAMRAssDNA is adsorbed on the surface of an MOF-La nanosheet, there is still a distance (ca. $8 \AA$ ) from the fluorescent groups (FAM or TAMRA) to the lanthanum ions (Figure $4 \mathrm{~b}$ ). This distance might block the effective charge transfer and affect the fluorescence quenching efficiency. From $\mathrm{La}^{3+}$ to $\mathrm{Tb}^{3+}$, the radius of the lanthanum ions is gradually reduced due to the lanthanide contraction. The larger size of the $\mathrm{La}^{3+}$ ion radius allows the fluorescent groups to be closer to the $\mathrm{La}^{3+}$ ion and effective fluorescence quenching can occur compared with the smaller sized $\mathrm{Nd}^{3+}, \mathrm{Eu}^{3+}$ and $\mathrm{Tb}^{3+}$ ions.

As revealed by the zeta potential measurements (Figure 4c), the surface of the MOF-Ln nanosheets was positively charged in pure a
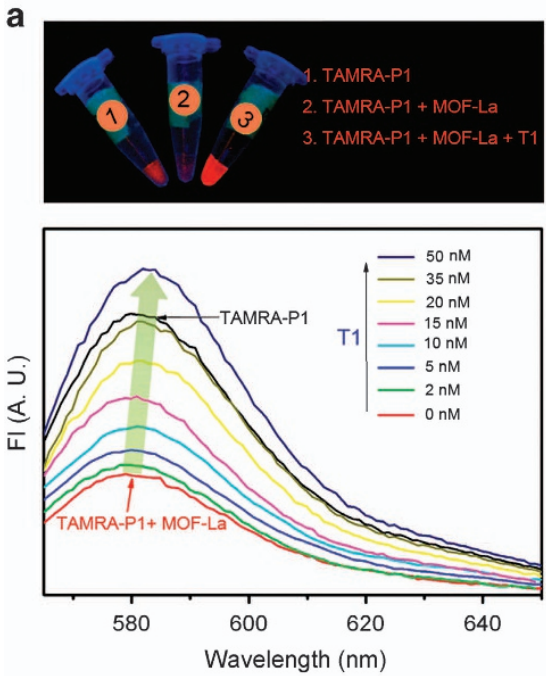

b
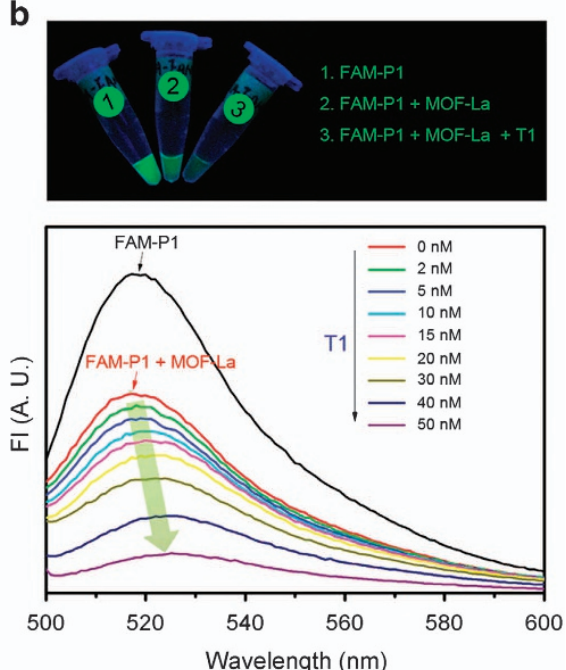

Figure 3 Fluorescence-quenching properties of MOF-Ln nanosheets. Fluorescence spectra of TAMRA-P1 (15 nM) (a) and FAM-P1 (20 nm) (b) with different concentrations of $\mathrm{T} 1(0,2,5,10,15,20,30,35,40$ and $50 \mathrm{~nm})$ in $10 \mathrm{~mm}$ PBS containing $0.2 \mathrm{mg} \cdot \mathrm{ml}-1$ of MOF-La nanosheets. The insets show the visible fluorescence changes of TAMRA-P1 (1.25 $\mu \mathrm{M})$ (a) and FAM-P1 (1.25 $\mu \mathrm{m})$ (b) irradiated under $365 \mathrm{~nm}$ light. 

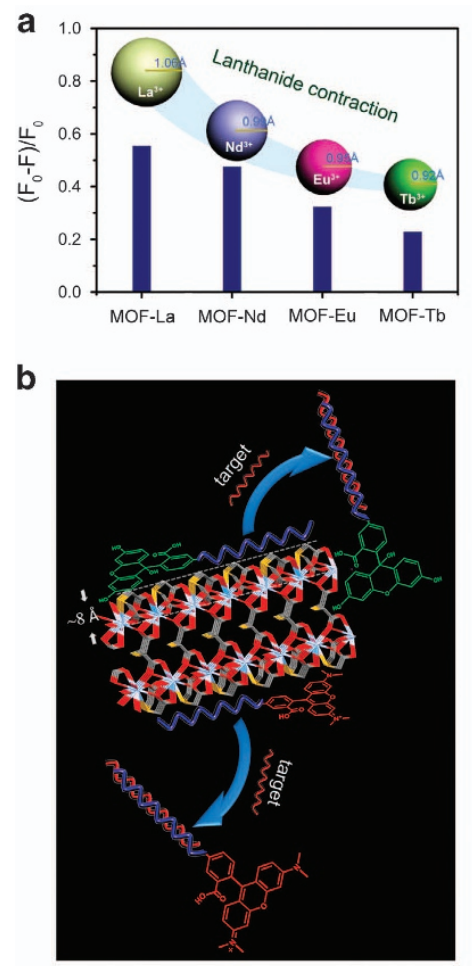

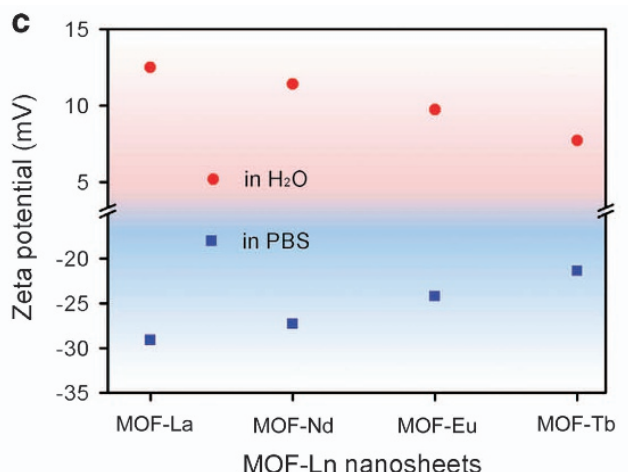

e

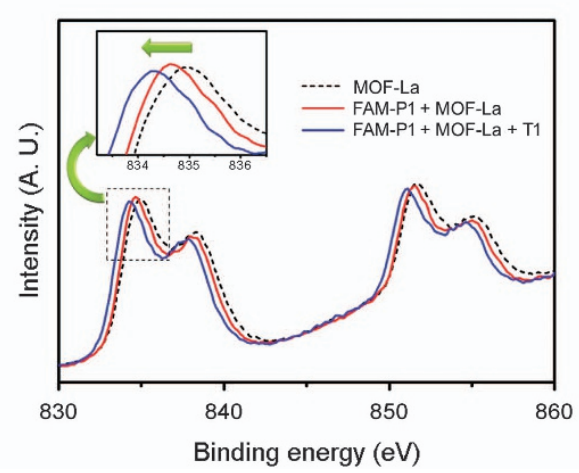

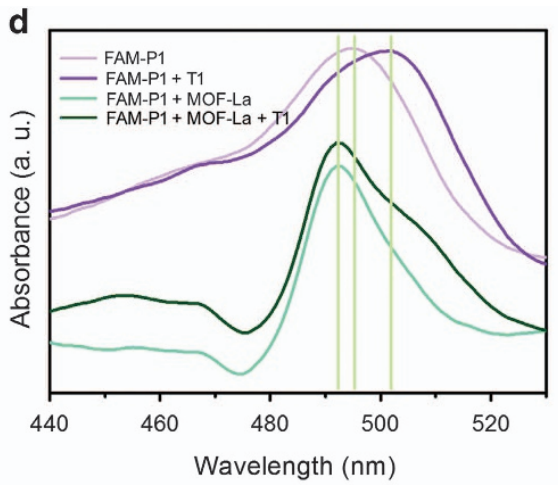

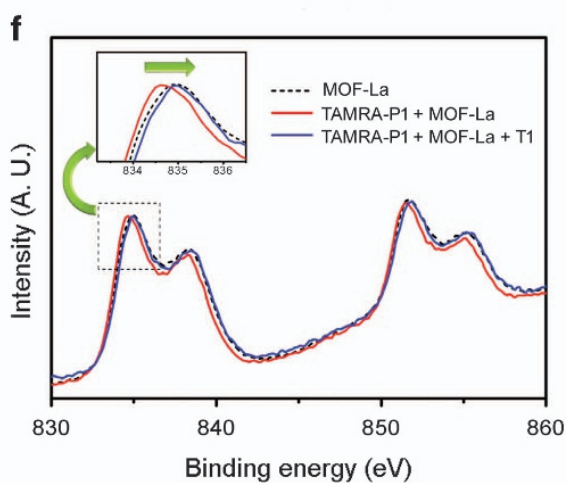

Figure 4 Characterization of dye-labeled DNA adsorption on MOF-Ln nanosheets. (a) Fluorescence-quenching efficiency of TAMRA-P1 on MOF-Ln nanosheets. $F_{0}$ and $F$ are the fluorescence intensities of TAMRA-P1 in the absence and presence of MOF-Ln nanosheets, respectively. (b) Schematic illustration of the adsorption of dye-labeled DNA on MOF-Ln nanosheets. (c) Zeta potentials of the MOF-Ln nanosheets in $\mathrm{H}_{2} \mathrm{O}$ and PBS. (d) UV-visible absorbance spectra of FAM-labeled DNA on MOF-La nanosheets. (e, f) X-ray photoelectron spectroscopy spectra of MOF-La nanosheets under different environments.

water, because the surface $\mathrm{Ln}^{3+}$ ions were not fully coordinated. The positive charge of the MOF-Ln nanosheets decreased with the decrease in ionic radius. It could be that the smaller $\mathrm{Ln}^{3+}$ ions were more easily embedded in the carbonyl groups on the edge of the MOF-Ln nanosheets. It was also observed that the MOF-Ln nanosheets were negatively charged in PBS due to the adsorption/coordination of $\mathrm{HPO}_{4}{ }^{2-}$ to the surface $\mathrm{Ln}^{3+}$ ions. The absolute negative charge of the MOF-Ln nanosheets decreased with the decrease in ionic radius, possibly due to steric inhibition on the smaller sized ions. As FAMssDNA hybridized with its complementary target DNA, the formed FAM- $d s$ DNA detached from the surface of the MOF-Ln nanosheets. Under experimental conditions, the negatively charged carboxyl and phenolic hydroxyl groups on FAM substituted the adsorbed $\mathrm{HPO}_{4}{ }^{2-}$ ions and adsorbed onto the edge of the MOF-Ln nanosheets, which allowed the re-adsorption of the detached FAM- $d s$ DNA to the positively charged edge of the MOF-Ln nanosheets where $\mathrm{Ln}^{3+}$ ions were not yet fully coordinated due to electrostatic attractions.

The adhesion of FAM- $d s$ DNA on MOF-La nanosheets was confirmed by detecting FAM- $d s$ DNA (FAM-P1+T1) residues in the supernatant obtained by centrifugation. As shown in Supplementary Figure S13A, after removing MOF-La nanosheets via centrifugation, the fluorescence intensity of the supernatant of FAM-P1+T1 was much lower than that of pure FAM-P1+T1, which demonstrated that most of the FAM-P1+T1 were adsorbed on the MOF-La nanosheets and removed by centrifugation. As expected, the fluorescence intensity of the supernatant of TAMRA-P1+T1 was similar to that of pure TAMRA-P1+T1 (Supplementary Figure S13B), indicating that almost all the TAMRA-P1+T1 were dissolved in solution instead of adsorbed on the MOF-La nanosheets.
The direct adsorption of FAM on $\mathrm{Ln}^{3+}$ ions shortens their distance, making the effective charge transfer occur easily from FAM to the $\mathrm{Ln}^{3+}$ ions. In fact, intensive fluorescence quenching of FAM- $d s \mathrm{DNA}$ on MOF-La nanosheets was observed with a quench efficiency of approximately $88 \%$ (Figure $3 \mathrm{~b}$ ). However, the TAMRA- $d s \mathrm{DNA}$ containing positively charged groups could not substitute the adsorbed $\mathrm{HPO}_{4}{ }^{2-}$; thus, it detached from the MOF-Ln nanosheets and its fluorescence was recovered.

The fluorescence-quenching mechanism for FAM- $d s$ DNA on MOFLa nanosheets was confirmed by UV-visible absorption and X-ray photoelectron spectroscopy (XPS) characterization. As described in Figure 4d, the FAM-ssDNA (FAM-P1) was characterized by an absorption band of FAM $(495 \mathrm{~nm})$. The addition of MOF-La nanosheets caused a blue shift of the Soret band of FAM. ${ }^{35}$ When the FAM-P1 hybridized with T1, the absorption band of the FAM$d s$ DNA was not recovered, indicating that the FAM- $d s$ DNA was still adsorbed on the MOF-La nanosheets. This phenomenon was also confirmed by XPS characterization (Figure 4e and f). The absorption of both FAM-P1 and TAMRA-P1 on MOF-La nanosheets caused blue shifts of the binding energy of $\mathrm{La}_{3 \mathrm{~d}}$ by approximately $1 \mathrm{eV}$. However, after P1 hybridized with T1, the TAMRA- $d s$ DNA detached from the surface of the MOF-La nanosheets and the binding energy of $\mathrm{La}_{3 \mathrm{~d}}$ was recovered, whereas the FAM- $d s$ DNA was attached on the edge of the MOF-La nanosheets and the blue shift of the binding energy of $\mathrm{La}_{3 \mathrm{~d}}$ was still observed. These results indicate that dye-labeled $s s \mathrm{DNA}$ can adsorb on the surface of MOF-La nanosheets. In the presence of target DNA, the formed TAMRA-labeled dsDNA will detach from the surface of MOF-Ln nanosheets, whereas the formed FAM-labeled $d s \mathrm{DNA}$ will remain attached to the edge of MOF-Ln nanosheets due to electrostatic interaction. 
a

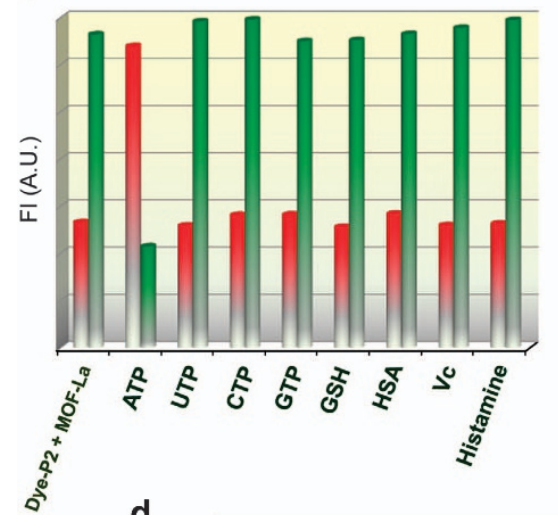

d

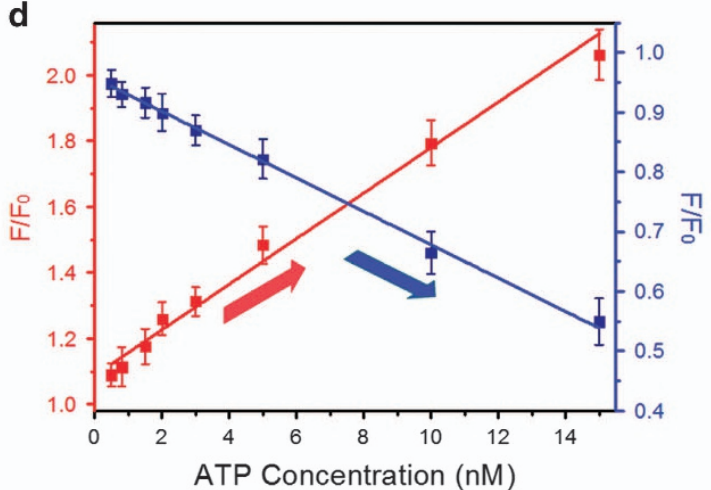

b

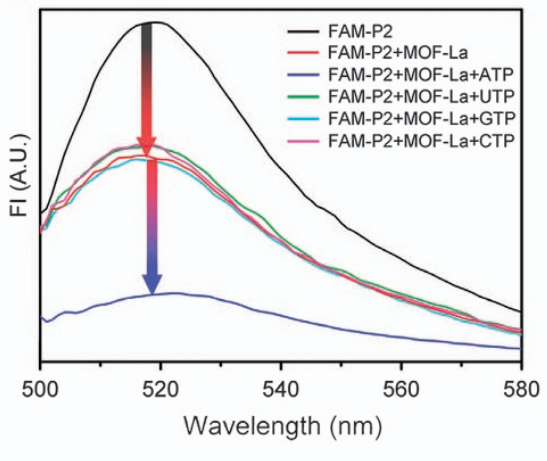

C

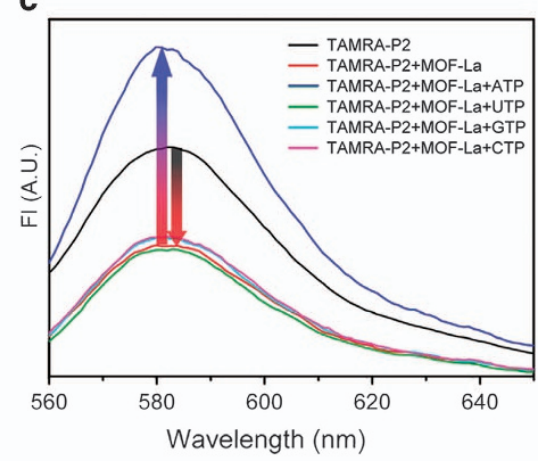

e

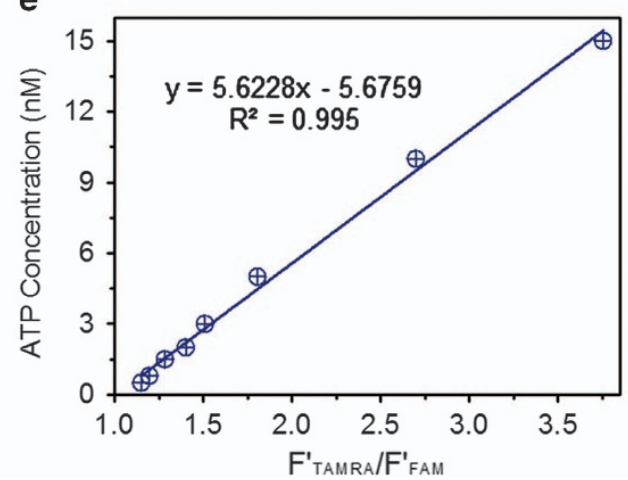

Figure 5 Selectivity of the MOF-La based adenosine sensor. (a) Peak fluorescence intensities of FAM-P2+MOF-La probe (the green bar, detected at $518 \mathrm{~nm}$ ) and TAMRA-P2+MOF-La probe (the red bar, detected at $582 \mathrm{~nm}$ ) for different biomolecules. (b, c) Fluorescence spectra of FAM-P2 (20 nM) (b) and TAMRAP2 (15 nm) (c) mixed with MOF-La nanosheets $\left(0.2 \mathrm{mg} \mathrm{ml}^{-1}\right)$ in the presence of ATP (uridine triphosphate (UTP), guanosine triphosphate (GTP) or cytidine triphosphate (CTP)) with concentrations of $30 \mathrm{~nm}$ (b) and $25 \mathrm{~nm}$ (c), respectively. (d) Calibration curves for adenosine detection (0.5-15 nM) according to $F_{\text {TAMRA }}$ (red) and $F_{\text {FAm }}$ (blue). (e) Calibration curve for adenosine detection (0.5-15 nm) based on the ratio of $F_{\text {TAmRA }} / F_{\text {FAM }}$.

Intracellular adenosine probing in living cells using MOF-Ln nanosheets as two-color sensing platforms

As a class of ssDNA/RNA molecules, aptamers have been used for molecular recognition with high affinity and specificity. ${ }^{36-39}$ In the present study, dye-labeled ATP aptamers on MOF-La nanosheets were used for intracellular two-color fluorescent imaging of ATP. The FAM-labeled ATP-aptamer (FAM-P2) and TAMRA-labeled ATPaptamer (TAMRA-P2) were incubated together with MOF-La nanosheets to form a Dye-P2+MOF-La complex, on which FAM-P2 and TAMRA-P2 were adsorbed with the same molar concentration. In the presence of target ATP, the specific binding of Dye-P2 with ATP induced the formation of a rigid structure. Similar to $d s \mathrm{DNA}$, the affinity of this rigid ATP aptamer conformation for the surface of MOF-La nanosheets was very weak. This ATP sensing was based on the turn-up of the fluorescence of TAMRA and the turn-down of the fluorescence of FAM, upon addition of target ATP.

The selectivity of the MOF-La-based adenosine sensor was tested by comparing the fluorescence intensity changes of FAM and TAMRA induced by ATP and other biomolecules, such as uridine triphosphate, cytidine triphosphate, guanosine triphosphate, human serum albumin, glutathione, ascorbic acid and histamine. As displayed in Figure $5 a-c$, ATP induced the fluorescence recovery of TAMRA on TAMRA-P2 + MOF-La and further quenched the fluorescence of FAM on FAM-P2 + MOF-La. In contrast, no obvious changes in fluorescence signals were observed when using the other biomolecules. These results indicated that the dye-P2+MOF-La biosensor exhibited good selectivity towards adenosines. In addition, the dye-P2+MOF-La biosensor also showed good selectivity toward adenosines in real samples, for example, human plasma and cell extracts (Supplementary Figure S14).

The peak fluorescence intensity ratio $F / F_{0}$ (where $F$ and $F_{0}$ are the peak fluorescence intensities in the presence and absence of the target, respectively) was plotted against the concentration of ATP (Figure 5d). The Dye-P2+MOF-La biosensor showed a linear range from 0.5 to $15 \mathrm{~nm}$ and a low detection limit of $500 \mathrm{pM}$ for ATP, comparable to previously reported values. ${ }^{5,40}$ Furthermore, a favorable linear correlation was observed between the $F / F_{0}$ of TAMRA-P2+MOF-La probe $\left(F_{\text {TAMrA }}^{\prime}\right)$ and the $F / F_{0}$ of FAM-P2+MOF-La probe ( $\left.F_{\text {FAM }}^{\prime}\right)$ (Figure 5e). The adenosine concentration can therefore be calculated based on the ratio of $F_{\text {TAMRA }}^{\prime} / F_{\text {FAM }}^{\prime}$.

In addition, the zeta potential of MOF-La nanosheets was $-29.1 \mathrm{mV}$ at $\mathrm{pH} 7.5$ in PBS (Supplementary Figure S15), which would allow the nanosheets to stably disperse in the biosystem. ${ }^{41}$ Based on the above characterizations, the dye-P2+MOF-La biosensor was used for intracellular adenosine probing in MCF-7 human breast cancer cells using confocal microscopy. After MCF-7, cells were incubated with dye-P2+MOF-La, the intracellular adenosine molecules interacted with the dye-P2 (Figure 6a). By irradiation with $488 \mathrm{~nm}$ light, a distinguishable fluorescence change was observed corresponding to FAM at $500-550 \mathrm{~nm}$ (green) and TAMRA at $550-650 \mathrm{~nm}$ (red). As shown in the merged images in Supplementary Figure S16, with the increase in incubation time, the 

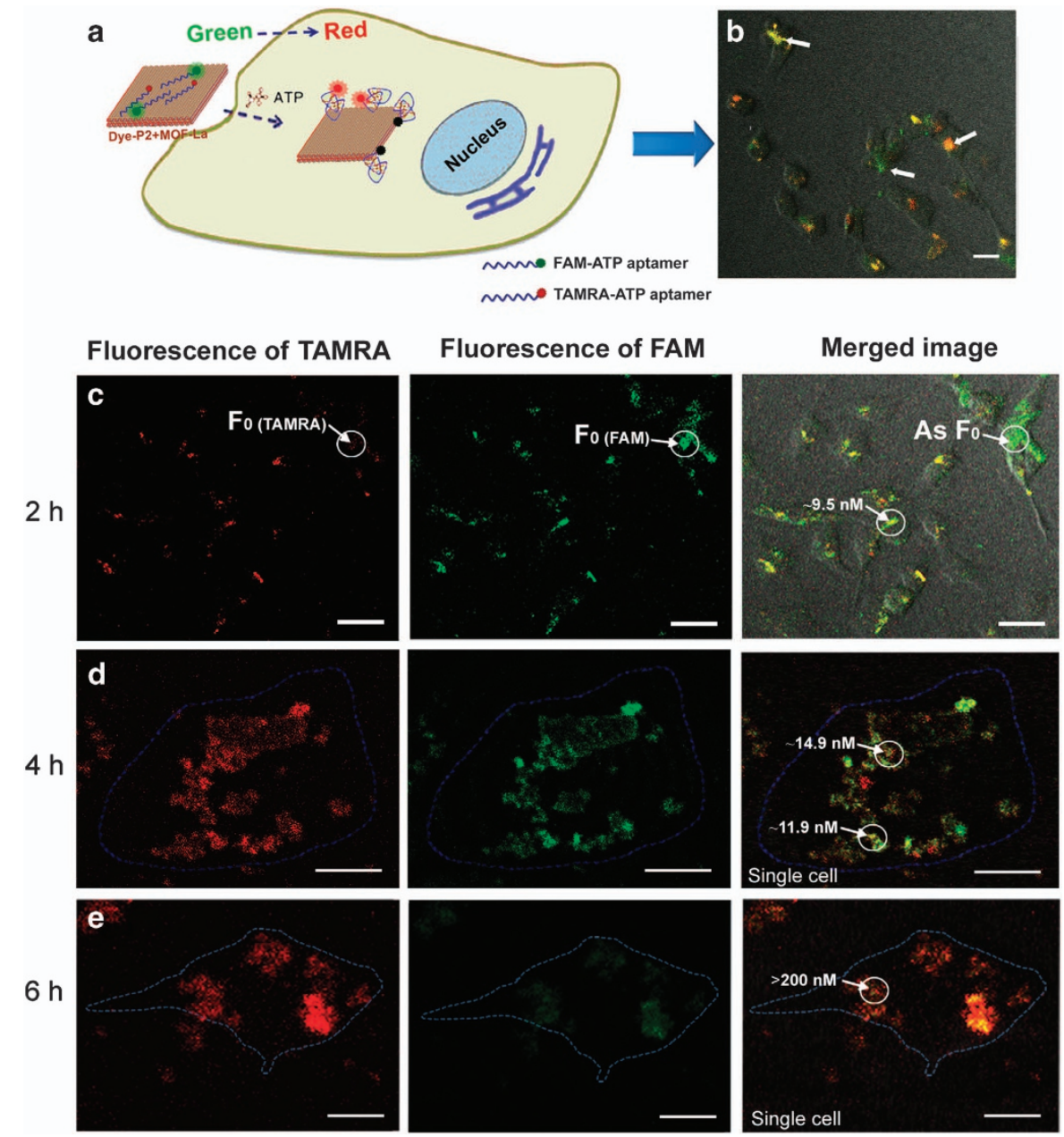

Figure 6 Intracellular fluorescent imaging of adenosines. (a) Schematic illustration of intracellular adenosine probing in living cells using dye-P2+MOF-La. (b) Monitoring of adenosine in living cells. (c-e) Confocal images of intracellular visualization for adenosines with an incubation time of 2 to $6 \mathrm{~h}$ and quantification of adenosines by two-color fluorescence. Scale bars: b, $25 \mu \mathrm{m} ; \mathbf{c}, 30 \mu \mathrm{m}$; d, e, $10 \mu \mathrm{m}$.

fluorescence color changed from kelly green to reddish orange. These findings indicated that the dye-P2 targeted adenosines to form the duplex configuration, resulting in the detachment of the dye molecules from the surface of the MOF-La nanosheets and the subsequent fluorescence recovery. The $\mathrm{Z}$ scanning experiment using confocal microscopy confirmed that the dye-P2+MOF-La had endocytosed into the MCF-7 cells (Supplementary Figure S17).

Adenosine activity in single cells was also monitored by the dye-P2 + MOF-La biosensor. As shown in Figure 6b, after incubating for $4 \mathrm{~h}$, the fluorescence color in different cells changed from green to red. The difference in color emission was also monitored in single cells (Figure 6c-e). Adenosine activity was clearly observed in different cells and different regions of a single cell. By calculating the ratio of $F_{\text {TAMRA }} / F_{\text {FAM }}^{\circ}$, the adenosine concentration in living cells was semidetermined (data indicated in Figure 6) based on the calibration curve in Figure 5e. The concentration of adenosines in living cells, incubated with the dye-P2+MOF-La biosensor for 2 or $4 \mathrm{~h}$, could be monitored from 0.5 to $15 \mathrm{~nm}$. When the incubation time was more than $6 \mathrm{~h}$, the ratios of $F_{\text {TAMRA }} / F_{\text {FAM }}^{\prime}$ were beyond the linear range of the method using the prepared dye-P2+MOF-La biosensor. For detecting high concentrations of adenosines ( $>15 \mathrm{nM}$ ), more FAM-P2 and TAMRAP2 should be incubated with the MOF-La nanosheets during the preparation of the dye-P2+MOF-La complex.
Considering that cellular ATP is predominantly produced in the mitochondria during aerobic respiration, ${ }^{42}$ the distribution of adenosines and mitochondria in living cells were monitored together. MitoTracker Deep Red FM (FMD, from YEASEN, Shanghai, China) (Supplementary Figure S18), a commercially available mitochondrial indicator, ${ }^{43}$ was employed for colocalization with mitochondria. As shown in Figure $7 \mathrm{a}-\mathrm{c}$, after the dye-P2+MOF-La and FMD were costained in MCF-7 cells, some of the adenosines were monitored around mitochondria. HeLa cells were also used to monitor the distribution of adenosines in living cells (Supplementary Figure S19). As adenosines generally exist in the mitochondria and cytosol, the distribution of adenosines did not overlap well with that of mitochondria (white color in Figure 7 and Supplementary Figure S19C; the excitation wavelength was $644 \mathrm{~nm}$ ).

In the control experiment, FAM-P3 (a FAM-labeled random DNA P3) and TAMRA-P3 (a TAMRA-labeled random DNA P3) were mixed with the MOF-La nanosheets to prepare a dye-P3+MOF-La complex, which was similar to the dye-P2+MOF-La complex. There was no obvious change in fluorescence intensity after the dye-P3+MOF-La complex was incubated with MCF-7 cells for $6 \mathrm{~h}$ (Supplementary Figure S20). These results reveal that the dye-P2+MOF-La complex can be used as a selective sensing probe for detecting biomolecules in living cells. 

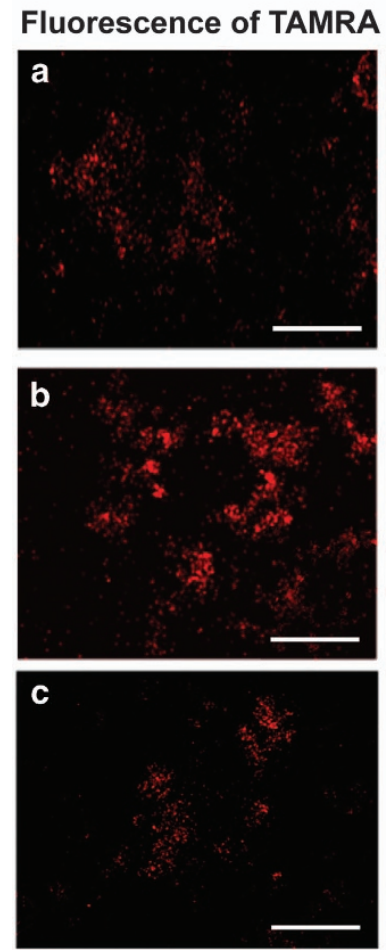
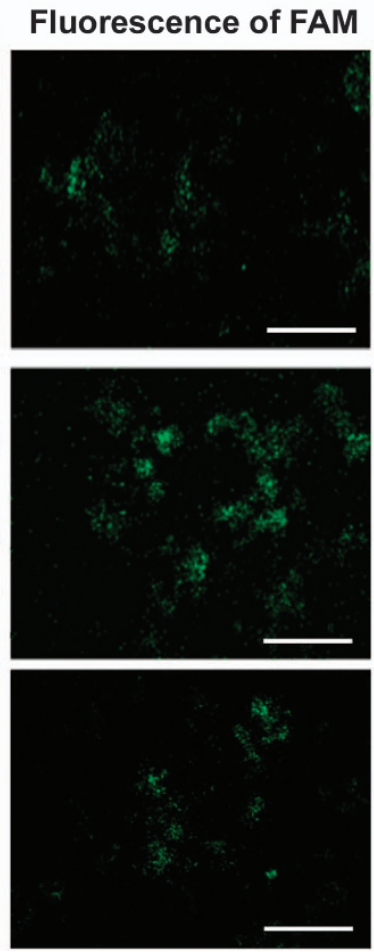

Merged image of FAM and TAMRA
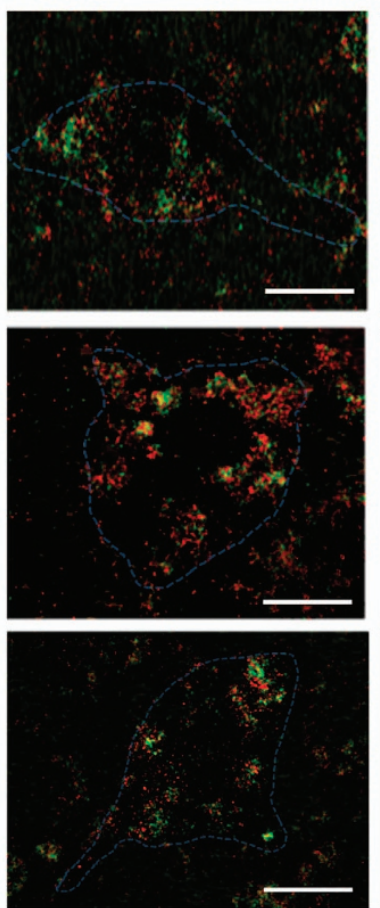

\section{Fluorescence of FMD}
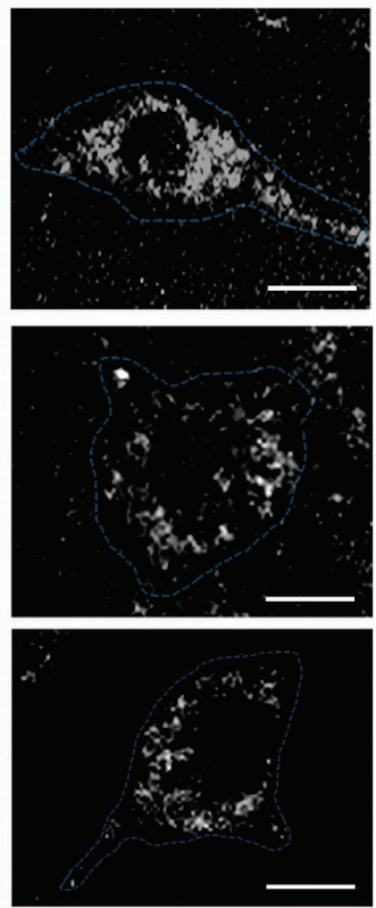

Figure 7 Confocal fluorescence images of MCF-7 cells incubated with dye-P2+MOF-La and FMD. (a-c) Single cells incubated with dye-P2+MOF-La and FMD for $4 \mathrm{~h}$. Scale bars: $10 \mu \mathrm{m}$.

\section{CONCLUSIONS}

We synthesized and characterized a series of ultrathin MOF-Ln nanosheets. These MOF-Ln nanosheets exhibited interesting fluorescence-quenching ability for dye-labeled DNA. The fluorescence of ssDNA labeled with FAM, carrying negative charges, was partially quenched by the MOF-Ln nanosheets. When hybridized with complementary target DNA, the FAM- $d s$ DNA detached from the surface of the MOF-Ln nanosheets and reattached to the edge of the nanosheets by electrostatic interaction between FAM and $\mathrm{Ln}^{3+}$. However, the fluorescence of ssDNA labeled with TAMRA, carrying positive charges, showed the same quenching and recovery properties on MOF-Ln nanosheets as on traditional 2D materials. We found that the MOF-La nanosheets exhibited better fluorescence-quenching ability than the MOF-Eu nanosheets because of the lanthanide contraction. By combining these advantages, the MOF-La nanosheets were successfully used as a two-color sensing platform for intracellular detection of DNA and small molecules. This work revealed the novel properties of MOF-Ln nanosheets. We believe that these nanosheets can be potentially used as a new type of platform for widespread biological applications.

\section{CONFLICT OF INTEREST}

The authors declare no conflict of interest.

\section{ACKNOWLEDGEMENTS}

This work was supported by grants from the National 973 Basic Research Program (number 2012CB933800), the National Natural Science Foundation of China (numbers 21275070, 21275071, 21327902 and 21635004) and Jiangsu Provincial Natural Science Foundation (number BK20150689).
1 Xiang, Z., Cao, D. \& Dai, L. Well-defined two dimensional covalent organic polymers: rational design, controlled syntheses, and potential applications. Polym. Chem. 6, 1896-1911 (2015).

2 Feng, L., Wu, L. \& Qu, X. New horizons for diagnostics and therapeutic applications of graphene and graphene oxide. Adv. Mater. 25, 168-186 (2013).

3 Yang, K., Feng, L., Shi, X. \& Liu, Z. Nano-graphene in biomedicine: theranostic applications. Chem. Soc. Rev. 42, 530-547 (2013).

4 Yuan, Y. X., Li, R. Q. \& Liu, Z. H. Establishing water-soluble layered $W_{2}$ nanosheet as a platform for biosensing. Anal. Chem. 86, 3610-3615 (2014).

5 Zhu, C., Zeng, Z., Li, H., Li, F., Fan, C. \& Zhang, H. Single-layer MoS 2 -based nanoprobes for homogeneous detection of biomolecules. J. Am. Chem. Soc. 135, 5998-6001 (2013).

6 Zhao, Z., Fan, H., Zhou, G., Bai, H., Liang, H., Wang, R., Zhang, X. \& Tan, W. Activatable fluorescence/MRI bimodal platform for tumor cell imaging via $\mathrm{MnO}_{2}$ nanosheet-aptamer nanoprobe. J. Am. Chem. Soc. 136, 11220-11223 (2014).

7 Ge, J., Ou, E. C., Yu, R. Q. \& Chu, X. A novel aptameric nanobiosensor based on the self-assembled DNA-MoS 2 nanosheet architecture for biomolecule detection. J. Mater. Chem. B 2, 625-628 (2014).

8 Tan, J.-C., Saines, P. J., Bithell, E. G. \& Cheetham, A. K. Hybrid nanosheets of an inorganic-organic framework material: Facile synthesis, structure, and elastic properties. ACS Nano 6, 615-621 (2012).

9 Junggeburth, S. C., Diehl, L., Werner, S., Duppel, V., Sigle, W. \& Lotsch, B. V. Ultrathin 2D coordination polymer nanosheets by surfactant-mediated synthesis. J. Am. Chem. Soc. 135, 6157-6164 (2013).

10 Cunningham, G., Lotya, M., Cucinotta, C. S., Sanvito, S., Bergin, S. D., Menzel, R., Shaffer, M. S. P. \& Coleman, J. N. Solvent exfoliation of transition metal dichalcogenides: dispersibility of exfoliated nanosheets varies only weakly between compounds. ACS Nano 6, 3468-3480 (2012).

11 Sumida, K., Rogow, D. L., Mason, J. A., McDonald, T. M., Bloch, E. D., Herm, Z. R., Bae, T. H. \& Long, J. R. Carbon dioxide capture in metal-organic frameworks. Chem. Rev. 112, 724-781 (2012).

12 Yoon, M., Srirambalaji, R. \& Kim, K. Homochiral metal-organic frameworks for asymmetric heterogeneous catalysis. Chem. Rev. 112, 1196-1231 (2012).

13 Gu, Z. Y., Yang, C. X., Chang, N. \& Yan, X. P. Metal-organic frameworks for analytical chemistry: from sample collection to chromatographic separation. Acc. Chem. Res. 45, 734-745 (2012).

14 Cui, Y., Yue, Y., Qian, G. \& Chen, B. Luminescent functional metal-organic frameworks. Chem. Rev. 112, 1126-1162 (2012).

15 Academic Emergency Medicine, Kreno, L. E., Leong, K., Farha, O. K., Allendorf, M., Van Duyne, R. P. \& Hupp, J. T. Metal-organic framework materials as chemical sensors. Chem. Rev. 112, 1105-1125 (2012). 
16 Carne, A., Carbonell, C., Imaz, I. \& Maspoch, D. Nanoscale metal-organic materials. Chem. Soc. Rev. 40, 291-305 (2011).

17 Della Rocca, J. \& Lin, W. Nanoscale metal-organic frameworks: Magnetic resonance imaging contrast agents and beyond. Eur. J. Inorg. Chem. 2010, 3725-3734 (2010).

18 Della Rocca, J., Liu, D. \& Lin, W. Nanoscale metal-organic frameworks for biomedical imaging and drug delivery. Acc. Chem. Res. 44, 957-968 (2011).

19 Rieter, W. J., Pott, K. M., Taylor, K. M. L. \& Lin, W. Nanoscale coordination polymers for platinum-based anticancer drug delivery. J. Am. Chem. Soc. 130, 11584-11585 (2008).

$20 \mathrm{He}, \mathrm{C} ., \mathrm{Lu}, \mathrm{K}$. \& Lin, W. Nanoscale metal-organic frameworks for real-time intracellular pH sensing in live cells. J. Am. Chem. Soc. 136, 12253-12256 (2014).

21 Liu, D., Huxford, R. C. \& Lin, W. Phosphorescent nanoscale coordination polymers as contrast agents for optical imaging. Angew. Chem. Int. Ed. 50, 3696-3700 (2011).

$22 \mathrm{Lu}, \mathrm{K} ., \mathrm{He}, \mathrm{C}$. \& Lin, W. Nanoscale metal-organic framework for highly effective photodynamic therapy of resistant head and neck cancer. J. Am. Chem. Soc. 136, 16712-16715 (2014)

$23 \mathrm{He}$, C., Lu, K., Liu, D. \& Lin, W. Nanoscale metal-organic frameworks for the Codelivery of cisplatin and pooled siRNAs to enhance therapeutic efficacy in drug-resistant ovarian cancer cells. J. Am. Chem. Soc. 136, 5181-5184 (2014).

24 Morris, W., Briley, W. E., Auyeung, E., Cabezas, M. D. \& Mirkin, C. A. Nucleic acid-metal organic framework (MOF) nanoparticle conjugates. J. Am. Chem. Soc. 136, 7261-7264 (2014).

25 Ramakrishna Matte, H. S. S., Gomathi, A., Manna, A. K., Late, D. J., Datta, R., Pati, S. K. \& Rao, C. N. R. $\mathrm{MoS}_{2}$ and $\mathrm{WS}_{2}$ analogues of graphene. Angew. Chem. Int. Ed. 49, 4059-4062 (2010)

26 Chung, C., Kim, Y. K., Shin, D., Ryoo, S. R., Hong, B. H. \& Min, D. H. Biomedical applications of graphene and graphene oxide. Acc. Chem. Res. 46, 2211-2224 (2013).

27 Pumera, M. \& Loo, A. H. Layered transition-metal dichalcogenides $\left(\mathrm{MoS}_{2}\right.$ and $\left.\mathrm{WS}_{2}\right)$ for sensing and biosensing. TrAC Trend. Anal. Chem. 61, 49-53 (2014).

28 Wang, H. S., Bao, W. J., Ren, S. B., Chen, M., Wang, K. \& Xia, X. H. Fluorescent sulfurtagged europium (III) coordination polymers for monitoring reactive oxygen species. Anal. Chem. 87, 6828-6833 (2015).

29 Taylor, K. M. L., Jin, A. \& Lin, W. Surfactant-assisted synthesis of nanoscale gadolinium metal-organic frameworks for potential multimodal imaging. Angew. Chem. Int. Ed. 47, 7722-7725 (2008).

30 Eda, G., Yamaguchi, H., Voiry, D., Fujita, T., Chen, M. \& Chhowalla, M. Photoluminescence from chemically exfoliated $\mathrm{MoS}_{2}$. Nano Lett. 11, 5111-5116 (2011).

31 Joensen, P., Frindt, R. F. \& Morrison, S. R. Single-layer MoS 2 . Mater. Res. Bull. 21, 457-461 (1986).

32 Zeng, Z., Yin, Z., Huang, X., Li, H., He, Q., Lu, G., Boey, F. \& Zhang, H. Single-layer semiconducting nanosheets: high-yield preparation and device fabrication. Angew. Chem. Int. Ed. 50, 11093-11097 (2011).

33 Lu, C. H., Yang, H. H., Zhu, C. L., Chen, X. \& Chen, G. N. A graphene platform for sensing biomolecules. Angew. Chem. Int. Ed. 48, 4785-4787 (2009).
34 Ryoo, S. R., Lee, J., Yeo, J., Na, H. K., Kim, Y. K., Jang, H., Lee, J. H., Han, S. W., Lee, Y., Kim, V. N. \& Min, D. H. Quantitative and multiplexed microRNA sensing in living cells based on peptide nucleic acid and nano graphene oxide (PANGO). ACS Nano 7 , 5882-5891 (2013).

35 Zhang, L., Tao, L., Li, B., Jing, L. \& Wang, E. Carbon nanotube-DNA hybrid fluorescent sensor for sensitive and selective detection of mercury(II) ion. Chem. Commun. 46, 1476-1478 (2010)

36 Zhao, X., Xu, L., Sun, M., Ma, W., Wu, X., Kuang, H., Wang, L. \& Xu, C. Gold-quantum dot core-satellite assemblies for lighting up microRNA in vitro and in vivo. Small 12, 4662-4668 (2016).

37 Sun, M., Xu, L., Ma, W., Wu, X., Kuang, H., Wang, L. \& Xu, C. Hierarchical plasmonic nanorods and upconversion core-satellite nanoassemblies for multimodal imagingguided combination phototherapy. Adv. Mater. 28, 898-904 (2016).

38 Xu, L., Zhao, S., Ma, W., Wu, X., Li, S., Kuang, H., Wang, L. \& Xu, C. Multigaps embedded nanoassemblies enhance in situ Raman spectroscopy for intracellular telomerase activity sensing. Adv. Funct. Mater. 26, 1602-1608 (2016).

39 Li, S., Xu, L., Ma, W., Wu, X., Sun, M., Kuang, H., Wang, L., Kotov, N. A. \& Xu, C. Dualmode ultrasensitive quantification of microRNA in living cells by chiroplasmonic nanopyramids self-assembled from gold and upconversion nanoparticles. J. Am. Chem. Soc. 138, 306-312 (2016).

40 Fu, P., Sun, M., Xu, L., Wu, X., Liu, L., Kuang, H., Song, S. \& Xu, C. A self-assembled chiral-aptasensor for ATP activity detection. Nanoscale 8, 15008-15015 (2016).

41 Wang, H., Wu, L. \& Reinhard, B. M. Scavenger receptor mediated endocytosis of silver nanoparticles into J774A.1 macrophages is heterogeneous. ACS Nano 6, 7122-7132 (2012).

42 Chen, L. B. Mitochondrial membrane potential in living cells. Annu. Rev. Cell Biol. 4, 155-181 (1988).

43 Zhou, L., Zhang, X., Lv, Y., Yang, C., Lu, D., Wu, Y., Chen, Z., Liu, Q. \& Tan, W. Localizable and photoactivatable fluorophore for spatiotemporal two-photon bioimaging. Anal. Chem. 87, 5626-5631 (2015).

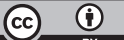

This work is licensed under a Creative Commons Attribution 4.0 International License. The images or other third party material in this article are included in the article's Creative Commons license, unless indicated otherwise in the credit line; if the material is not included under the Creative Commons license, users will need to obtain permission from the license holder to reproduce the material. To view a copy of this license, visit http:// creativecommons.org/licenses/by/4.0/

(C) The Author(s) 2017

Supplementary Information accompanies the paper on the NPG Asia Materials website (http://www.nature.com/am) 